Çukurova Üniversitesi Mühendislik Mimarlık Fakültesi Dergisi, 31(ÖS 2), ss. ÖS 15-ÖS 20, Ekim 2016

\title{
Yeni Bir Eddy Akımı Ayrıştırıcısı ile Küçük Boyutlu Demirsiz Metallerin Ayrıştırılması
}

\author{
Ahmet FENERCIOĞLU ${ }^{* 1}$, Hamit BARUTÇU ${ }^{1}$ \\ ${ }^{1}$ Gaziosmanpaşa Üniversitesi, Mühendislik ve Doğa Bilimleri Fakültesi, Mekatronik \\ Mühendisliği Bölümü, Tokat
}

Geliş tarihi: 20.08.2016

Kabul tarihi: 30.09 .2016

$\ddot{\mathbf{O} z}$

Bu çalışmada 5 mm'den küçük granül haldeki demirsiz metallerin ayrıştırılarak geri kazanımı amacıyla tasarlanan yeni bir eddy akımı ayrıştırıcısı (EAA)'nın performansı incelenmiştir. Ayrıştırılacak malzemenin küçüklüğünden dolayı oluşan itme kuvveti ayrıştırmada yetersiz kalmaktadır. Bu kuvveti artırabilmek için mıknatıs tambur tasarımı, tambur hızı, kutup sayısı, hava aralı̆̆ı, mıknatıs seçimi ve ana gövde tasarımında yapılacak iyileştirmeler ile yeni bir EAA geliştirilmiştir. Bu etkilerin deneyle incelenmesi mümkün olduğu için tambur pozisyonunun değişimi, tambur ve konveyör hızının etkileri test edilerek performansa etkileri belirlenmiştir. Bu sistem ile granül atık içerisinde bulunan değerli metallerin yüksek verimle geri dönüşümü ve ekonomiye kazandırılması mümkün olmaktadır. Granül atık halindeki güç kablolarının ayrıştırılması için yapılan deneylerde en az \%96'nın üzerinde verim elde edilmiştir.

Anahtar Kelimeler: Eddy akımı ayrıştırıcısı, Değerli metal ayrıştırma, Demirsiz metal ayrıştırma

\section{Separation of Small Sized Non-Ferrous Metals with a Novel Eddy Current Separator}

\begin{abstract}
In this study; performance of novel eddy current separator (ECS) is designed for particle separation is examined for separation of non-ferrous metals smaller than $5 \mathrm{~mm}$. The propulsion force in material is not sufficient due to small size for separation. Drum design and speed, number of magnet poles, airgap, magnet type an main frame design are improved to increase the propulsion force. Variations of drum position, drum and conveyor speed are examined by experiments for determation of performance effects. It is possible that recycling of granule nonferrous valuable metals, and obtainig economical value with high efficiency. In experiment of granule power cable wastes separation efficiency is higher than $\% 96$.
\end{abstract}

Keywords : Eddy current separator, valuable metal separation, Non-ferrous metal separation

\footnotetext{
*Sorumlu yazar (Corresponding author): Ahmet FENERCiOĞLU, ahmet.fenercioglu@gop.edu.tr
} 


\section{GİRIŞ}

Ayrıştırmada öncelikli işlem malzemeleri sinıflandırdıktan sonra ayrı ayrı parçalayarak geri kazanmaktır. Fakat değerli metallerin birada montaj halinde olduğu veya plastik k1lıfla birlikte bulunduğu durumlarda bunları birbirinden ayırmak oldukça zordur ve yüksek işçilik maliyetleri gerektirir. Bu tür malzemeler kıyıcı makinelerde hepsi bir arada parçalanmaktadır. Parçalanmış atıklar granül olarak karışık halde bulunurlar. Öngörülen sistem ile bu karışım içerisinden değerli metalleri ayrıştırmak mümkündür. Süreç içerisinde EAA ferromanyetik malzemeleri ayrıştırmada kullanılmadı̆̆ı için öncelikle atık içerisinde demir içeren metaller bir elektromıknatısla tutularak dışarı alınmalıdır. Kalan atıklar ise bant üzerinde taşınarak EAA yardımıyla ayrıştırılmaktadır. Ayrıştırma sonucunda değerli metaller bir bölmeye alınırken kalan diğer malzemeler başka bir bölmeye alınmaktadır. Şekil 1'de demirsiz metallerin ayrıştırılmasını gösteren EAA'nın prensip şeması verilmiştir [1-2]

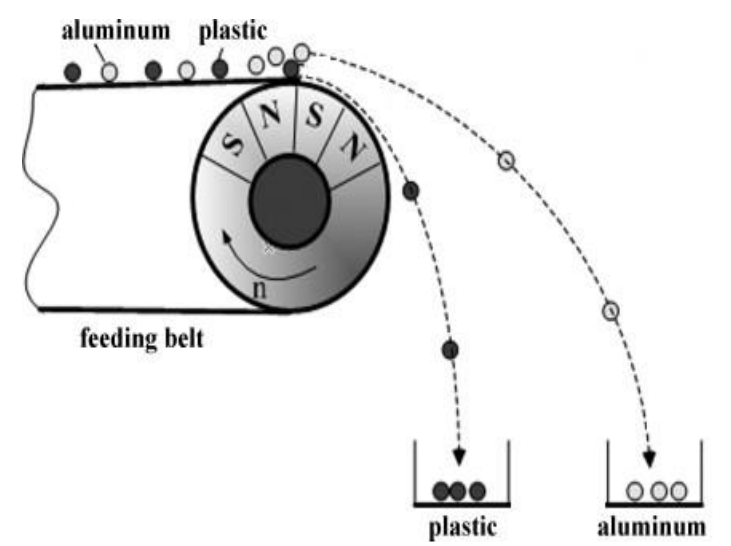

a)

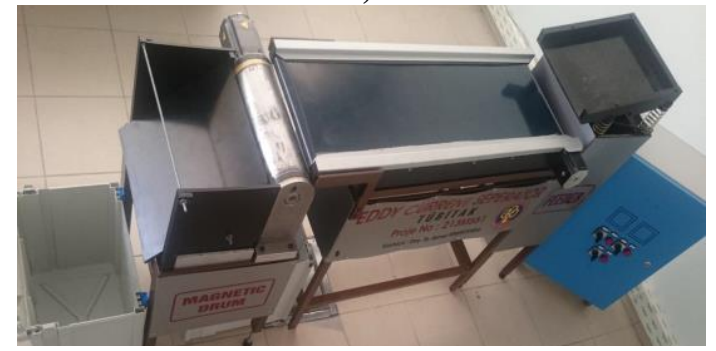

b)

Şekil 1. EAA a) prensip şeması, b) prototip
$\mathrm{Bu}$ çalışmada granül haldeki değerli metallerin ayrıştırmak amacıyla tasarlanan EAA'nın performansı için bazı parametreler incelenecektir. Ayrıştırılacak malzemenin küçüklüğünden dolayı oluşan itme kuvveti ayrıştırmada yetersiz kalmaktadır. Bu kuvveti artırabilmek için mıknatıs tambur tasarımı, tambur hizı ve kutup sayıs1, hava aralığı, mıknatıs seçimi ve ana gövde tasarımında iyileştirmeler ile yeni bir EAA tasarımı geliştirilmiş ve 213M551 nolu Tübitak destekli bir proje kapsamında prototip olarak imal edilmiştir.

$\mathrm{Bu}$ çalışmada tamburun $\mathrm{X}$ ve $\mathrm{Y}$ eksenlerindeki konumu, tambur h1zı, tambur ile malzeme arasındaki hava aralığı ve malzemeyi tambur üzerine taşıyan bant hızının ayrıştırma verimine etkileri incelenmiştir. Bu sistem ile granül atık içerisinde bulunan değerli metallerin yüksek verimle geri dönüşümü sağlanarak hammaddeye dönüşümü ve ekonomiye kazandırılması mümkün olmaktadır. Geri dönüşümle kazanılan bu değerli metaller sayesinde bu madenlerin çıkarılması ve işlenmesi için harcanan işçilik ve enerji azalacaktır. Böylece doğal kaynaklar korunarak çevre daha az kirletilecektir. Ayrıca EAA'nın teknolojisi ve tasarımı konusunda yapılacak Ar-Ge çalışmaları sistemi üretmek isteyen makine-imalat firmalarına yön göstermesi ve ürünün ticarileştirilmesi hedeflenmektedir.

\section{2. ÖNCEKİ CALISMMALAR}

Genel anlamda uluslar arası düzeyde EAA'lar ile ilgili oldukça az yayın ve akademik çalışmaya rastlanmıștır. Yurtiçinde ise yok denecek kadar az sayıda yayın bulunmaktadır.

Yapılan çalışmaların çoğunluğu $5 \mathrm{~mm}$ den küçük boyutlu demirsiz metallerin ayrıştırılabilmesi için performans artırmayı hedefleyen çalışmalardır. Bu kapsamda tasarım değişiklikleri, tasarım doğrulama çalışmaları, EAA'nın simülasyonları ve sonlu elemanlar yöntemi ile analizleri, deneysel çalışmalarla farklı metaller için performansın belirlenmesi, tambur ve konveyör bant hızlarının verime etkisi, ayrıştırılacak malzemenin özkütle, iletkenlik ve şekil faktörünün performansa etkileri konularında literatürde çalışmalar bulunmaktadır [3-11]. 


\section{MATERYAL VE METHOD}

Demir içermeyen değerli metallerin ayrıştırılması için, eddy akımı etkin bir yöntemdir. Eddy akımı prensibi; bir iletken malzeme değişken bir manyetik alan içerisine yerleştirildiğinde manyetik akı tarafindan kesilerek Faraday kanununa göre malzemede bir elektrik yükü indüklenir. Kapalı devre olan malzemede Eddy akımı olarak adlandırılan girdap şeklinde akımlar geçer. $\mathrm{Bu}$ akıma girdap akımı da denilmektedir. Eddy akımların etkisi ile malzemede Ampere kanununa göre manyetik alan oluşmaktadır. Bu alan mıknatıs bloklarından oluşan tamburun manyetik alanından etkilenir. Her iki alanın etkisi ile Biot-Savart yasasına göre malzemede kuvvet oluşur. $\mathrm{Bu}$ itme kuvveti ile malzeme ürün akışından dışarıya atılır. Şekil 2'de döner tamburlu tip EAA üzerinde gösterilmektedir.
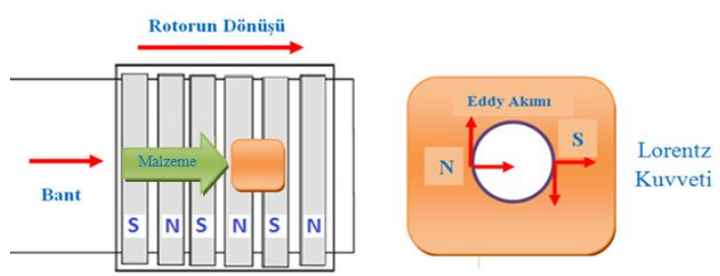

Şekil 2. Döner tamburlu EAA'nın üsten görünüşü

Şekil 2'de görülen döner tamburlu Eddy akım ayrıştırıcısında, döner mıknatıslı tamburun değişken manyetik alanının yol açtığ 1 itici kuvveti Eşitlik 1 ve 2 ile sade biçimde ifade edilmiştir [8].

$$
\begin{aligned}
& F_{r}=H^{2} f \times \frac{m \sigma}{\delta s} \\
& f=\frac{n p}{2}
\end{aligned}
$$

Burada $F_{r}$ firlatma kuvvetini, $H$ manyetik alan şiddetini, f manyetik alan frekansını, n mıknatıs tamburun hızını, p manyetik kutup sayısını, m kütleyi $\sigma$ iletkenlik oranını, $\rho$ malzemenin şekil ve yoğunluk faktörünü ifade etmektedir. Farklı malzemeler için, bileşik kuvvet malzeme özellikleri ile ilgilidir ve iletkenliğin yoğunluğa oranı $(\sigma / \rho)$ kuvvetin boyutunu ve ayrıştırma zorluğunun derecesi belirlemektedir. $\mathrm{Bu}$ oranın büyük olduğu malzemelerde ayrıştırma başarısı daha yüksektir $[4,8,9]$.
$\mathrm{Bu}$ malzemeler yaklaşık $2 \mathrm{~mm}$ çapında $5 \mathrm{~mm}$ uzunluğundadır. $\mathrm{Bu}$ deneyler için belirli miktarda malzeme seçilmiş ve farklı parametrelerin belirlenen malzemelerin ne kadarını ayrıştırdığı tespit edilerek ayrıştırma verimi belirlenmiştir (Şekil 3). Malzeme olarak $70 \mathrm{~g}$ alüminyum ve $180 \mathrm{~g}$ bakır seçilmiştir [4].

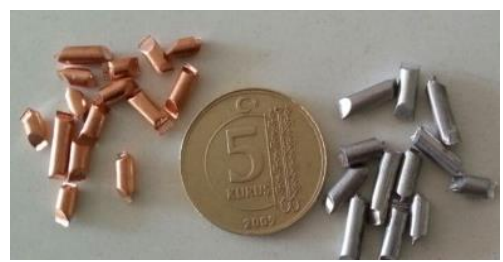

Şekil 3. Ayrıştırma verimi deneylerinde kullanılan malzemeler

Tasarlanan EAA'da malzemelerin düşeceği kap bölmelerine iki adet kutu yerleştirilmiş ve ayrıştırma işleminden sonra bu kapların içindeki malzeme miktarları yine hassas terazi ile ölçülmüş ve ayrıştırma verimi belirlenmiştir. Bu deneylerde tambur hizı, tambur konumu, malzeme cinsi ve bant hızı gibi parametrelerin ayrıştırma verimine etkisi belirlenmiştir. Tambur konumunun etkisi X ve Y koordinatları için ayrı ayrı olarak belirlenmiştir.

\section{BULGULAR}

\subsection{Tambur Pozisyonunun Verime Etkisi}

Tambur pozisyonun $\mathrm{X}$ eksenindeki değişiminin ayrıştırma verimine etkisini gözlemlemek için tambur Y ekseninde -3 cm'de, tambur hiz1 2000 rpm'de sabit tutulmuştur. Bant hızı ise $0,3 \mathrm{~m} / \mathrm{sn}$ olarak belirlenmiştir. Tamburun $\mathrm{x}$ ve $\mathrm{y}$ eksenindeki konumunu Şekil 4'de gösterilmiştir.

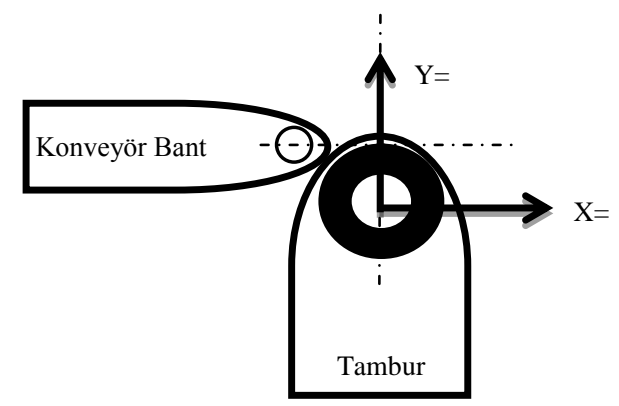

Şekil 4. Tamburun X ve Y eksenine göre konumu 
Tamburun $\mathrm{X}$ eksenindeki 0,1 ve $2 \mathrm{~cm}$ konumları için ne kadar malzemenin ayrıştığı tespit edilmiştir. İlk olarak alüminyum daha sonra bakır malzeme kullanılarak deney tamamlanmıştır. Bakır ve alüminyum malzeme için tamburun $\mathrm{X}$ eksenindeki konumuna göre ayrıştırma verimi Şekil 5'de gösterilmiştir.

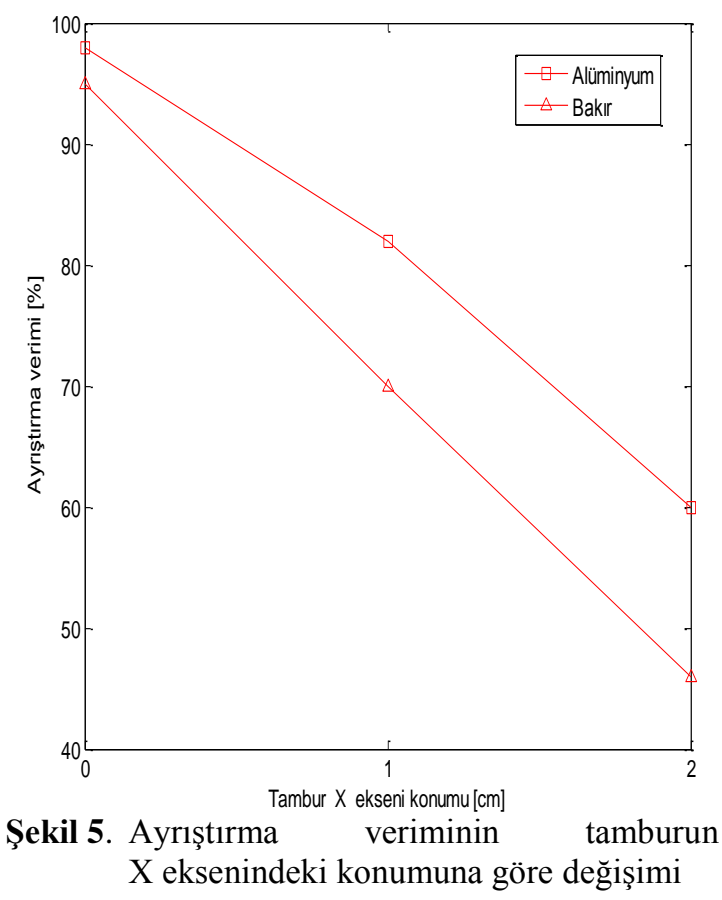

Sonuçlara bakıldığında her iki malzeme için de tamburun X eksenindeki konumu arttırıldığında yani tambur ve bant birbirinden uzaklaştığında ayrıştırma verimi düşmektedir. Bunun sebebi tambur banttan uzaklaştığında daha az malzemenin tambur üstüne gelmesidir. Böylece ayrıştırma veriminin tamburun $\mathrm{X}=0$ konumu için en yüksek değerde olduğu tespit edilmiştir.

Tamburun Y eksenindeki konumu için ayrıştırma verimi incelenmiştir. Tambur $\mathrm{X}=0$ konumunda sabit tutulmuştur. Tambur hızı 2000 rpm'de bant hızı ise $0,3 \mathrm{~m} / \mathrm{s}$ olarak sabit tutulmuştur. Tamburun Y eksenindeki -2 , -3 ve -4 cm'deki konumları için ayrıştırma işlemi gerçekleştirilmiş ve verimler incelenmiştir. Tamburun Y eksenindeki konumu için ayrıştırma verimi Şekil 6'da verilmiştir.
Deney sonuçları incelendiğinde tamburun Y ekseninde banttan uzaklaştığında verimin düştüğü görülmüştür. Tambur bant seviyesinden ne kadar aşağıda olursa malzeme banttan düştüğünde daha fazla potansiyel enerjiye sahip olacaktır. Dolayısıyla tamburun manyetik alanının oluşturduğu kuvvet malzeme ile birlikte bu potansiyel enerjisini de karşılamaya yetmeyecektir. Ayrıştırma verimi $\mathrm{Y}=-2$ konumu için en yüksek değerine sahiptir.

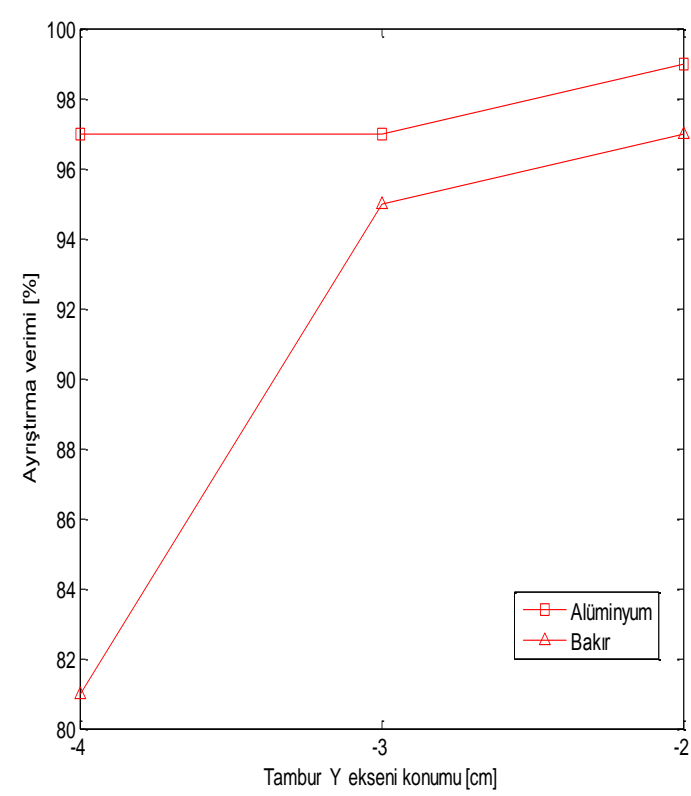

Şekil 6. Ayrıştırma veriminin tamburun Y eksenindeki konumuna göre değişimi

\subsection{Tambur Hızının Ayrıştırma Verimine Etkisi}

Tamburun X-Y eksenlerinde ayrıştırma veriminin en yüksek olduğu konumları belirlenmiştir. $\mathrm{Bu}$ deney de ise tambur hızının ayrıştırma verimine etkisi incelenmiştir. Tambur $\mathrm{X}=0$ ve $\mathrm{Y}=-2$ konumunda, bant h1z1 ise $0,3 \mathrm{~m} / \mathrm{sn}$ 'de sabit tutulmuştur. Yine $70 \mathrm{~g}$ alüminyum granül malzeme besleme ünitesine konulmuş ve ayrıştırma işlemi tambur hızının 500 ile $3000 \mathrm{rpm}$ arasındaki hız değerleri için ayrı ayrı yapılmıştır. Alüminyum ve bakır için deney sonuçları grafik olarak Şekil 7'de verilmiştir. 


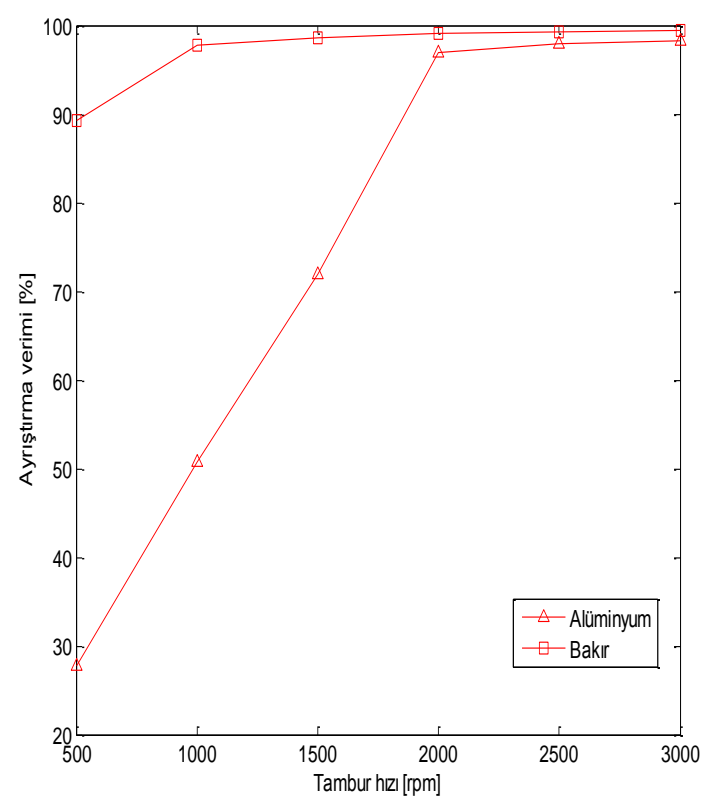

Şekil 7. Tamburun hızına göre verimin değişimi

$\mathrm{Bu}$ deney sonuçlarını incelediğimizde hız arttıkça ayrışan malzeme miktarı yükselmiştir. Öyleki 3000 rpm'de $70 \mathrm{~g}$ alüminyum malzemenin \%99'dan fazlası $180 \mathrm{~g}$ bakır malzemenin \%98'den fazlası ayrıştırılmıştır.

\subsection{Bant Hızının Ayrıştırma Verimine Etkisi}

$\mathrm{Bu}$ deneyde ise bant hızının ayrıştırma verimine etkisinin gözlemlenmesi hedeflenmiştir. Deneyde tambur hızı 2000 rpm'de sabit tutulmuştur. Tambur $X=0$ ve $Y=-2$ konumunda iken bant hızının 0,1 ile $0,5 \mathrm{~m} / \mathrm{sn}$ arasındaki değerler için ayrıştırma işlemi yapılmıştır ve sonuçlar Şekil 8'deki grafikte karşılaştırılmıştır.

Deney sonuçları incelendiğinde bant hızının artması ile ayrıştırma veriminin de arttığı görülmüştür. Bant hızı arttığında bant malzemeyi bitiş noktasında daha fazla ötelemektedir. Bundan dolayı miknatis tamburun manyetik alanı malzemeye daha fazla kuvvet uygulamaktadır. Fakat bant hızını belirli bir değerden fazla artırıldığında pvc atıkların da eylemsizlikten dolayı ayrıştırılan metal içerisine düşebilmektedir. $\mathrm{Bu}$ nedenle $0,3 \mathrm{~m} / \mathrm{s}$ optimum bant hızı olarak belirlenmiştir.

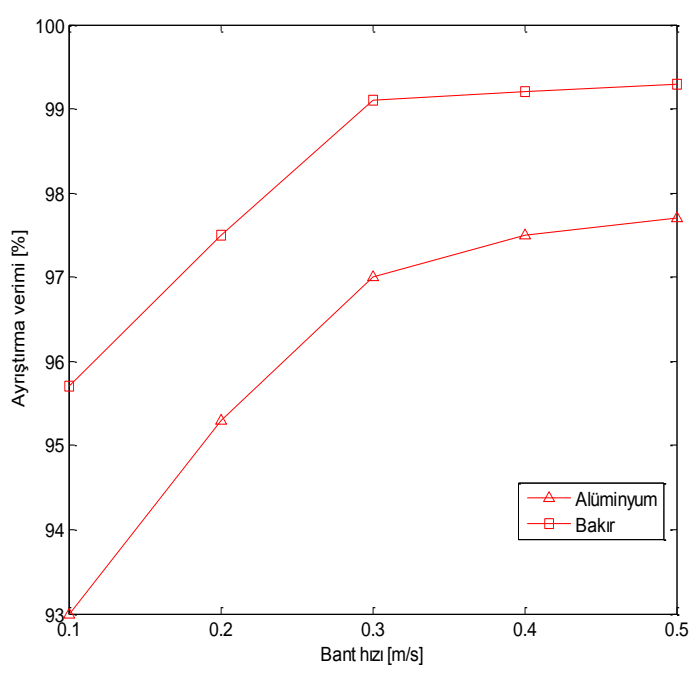

Şekil 8. Bant hızına göre verimin değişimi

\section{SONUÇ}

Ayrıştırma verimi deneylerinde, mıknatıslı tamburun dönüş hızının, mıknatıslı tamburun konumunun, bant hızının ve malzeme cinsinin ayrıştırılan malzeme miktarına etkisi olduğu tespit edilmiştir. Prototipin miknatıslı tamburu $500 \mathrm{rpm}$ hızda çalıştığında alüminyum malzeme için yaklaşık \%90 ayrıştırma verime, bakır malzeme için \%25 sahip iken, 3000 rpm'de alüminyum malzemede yaklaşık \%99, bakır malzeme için \%98 ayrıştırma verimine sahiptir.

Bant hızının da ayrıştırma verimine etki ettiği görülmüş ve bant hızının ayrışan malzeme miktarını değiştirdiği tespit edilmiştir. Bant $0,1 \mathrm{~m} / \mathrm{s}$ hızda çalışırken alüminyum malzeme kullanıldığında ayrıştırma verimi \%96, bakır malzeme için verim \%93 olmuştur. Bant hızı $0,5 \mathrm{~m} / \mathrm{sn}$ olduğunda alüminyum malzeme için verim \%99 ve bakır malzeme için verim yaklaşık \%98 olmuştur. Bu deneylerde alüminyum ve bakır malzemeler için ayrıştırma veriminin farklı olduğu görülmüş ve malzeme cinsinin de ayrışma verimini etkilediği gözlemlenmiştir. Bakırın iletkenliği daha yüksek olduğu için malzemede indüklenen kuvvet daha yüksektir. Fakat özgül ağırlığı yüksek olduğu için oluşan kuvvet yeterli düzeyde malzemeyi fırlatamadığı için bakırdaki verim daha düşüktür. 
Öngörülen ayrıștırıcı ile değerli metallerin birarada montaj halinde olduğu veya plastik ile birlikte bulunduğu durumlarda bunları birbirinden ayırmak mümkün olacaktır ve yüksek işçilik maliyetlerine gerek kalmayacaktır. Parçalanmış atıklar granül olarak karışık halde bulunduğundan öngörülen sistem ile bu karışım içerisinden değerli metalleri ayrıştırmak mümkün olmuştur. Süreç içerisinde EAA demir içeren malzemeleri ayrıştırmada

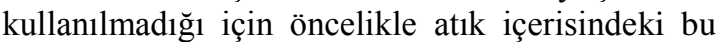
metaller bir elektromıknatısla tutularak dışarı alınmalıdır. Kalan atıklar ise bant üzerinde taşınarak EAA yardımıyla ayrıştırılmaktadır. Ayrıştırma sonucunda alüminyum, bakır, pirinç gibi değerli metallerin ayrıştırılarak hammadde üretimine geri dönüşümü sağlanabilir.

$\mathrm{Bu}$ ayrıştırma işleminin etkin olarak yapılması sonucunda; önemli miktarda ekonomik fayda ve enerji tasarrufu sağlanacak, insan sağlığını olumsuz etkileyen unsurlar kısmen giderilecek, çevrenin korunmasına katkı sağlanmış olacaktır.

\section{TEŞEKKÜR}

$\mathrm{Bu}$ çalışma 213M551 nolu proje kapsamında TÜBİTAK tarafından desteklenmiştir.

\section{KAYNAKLAR}

1. Dobney, S.J., 1993. Eddy Current Separators, IEE Colloquium on Permanent Magnet Machines and Drives, London, 9, pp: 1-3.

2. Fenercioğlu, A., Kurt, Ü., 2007. Manyetik Olmayan İletken Malzemelerin Ayrıştırılmasında Eddy Akımı Yönteminin Kullanılması ve Alüminyumun Geri Kazanılması Örneği, UMES 2007, Kocaeli 2, pp: 712-715.

3. Fenercioğlu, A., Barutçu, H., 2015. Finite Element Analysis of Separation Force on NonFerrous Metals Induced by Eddy Current Separator, PIERS 2015, 6-9 July, 2015, Prague, Czech Republic.

4. Fenercioğlu, A., Barutçu, H., 2015. Separation of Granule Non-Ferrous Metals in Shredded Cable Waste with Eddy Current Separator, Proceedings of the $4^{\text {th }}$ International Conference on Mechanics and Industrial Engineering, 20-21 July, 2015, Barcelona, Spain.

5. Kang, H.Y., Schoenung J.M., 2005. Electronic Waste Recycling: A Review of U.S. Infrastructure and Technology Options, Resources Conversation Recycling 45, pp: $368-400$.

6. Lungu, M., Rem, P., 2003. Eddy-current Separation of Small Nonferrous Particles by a Single-Disk Separator with Permanent Magnets, IEEE Transactions on. Magnetics, 39 (4), pp: 2062-2067.

7. Lungu, M., 2005. Separation of Small Nonferrous Particles using an Angular Rotary Drum Eddy-current Separator with Permanent Magnets, International Journal of Mineral Processing, 78, pp: 22-30.

8. Wang, Q., Zhao, Y., Jiao, H., Zhang, H., 2005. Effects of Operation Parameters of Eddy Current, $7^{\text {th }}$ World Congress on Recovery, Recycling and Re-integration, China.

9. Zhang, S., Rem, P.C., Forssberg, E., 1999. Particle Trajectory Simulation of Two-drum Eddy Current Separators, Res. Conserv. Recycl. 26, pp: 71-90.

10.Zhang, S., Rem, P.C., Forssberg, E., 1999. The Investigation of Separability of Particles Smaller than $5 \mathrm{~mm}$ by Eddy-current Separation Technology, Part I: Rotating Type Eddy-current Separators. Magn. Electr. Separators, pp: 233-251.

11.Zhang, S., Forssberg, E., Arvidson, B., Moss, W., 1999. Separation Mechanisms and Criteria of a Rotating Eddy Current Separator Operation, Resources, Conservation and Recycling 25, pp: 215-232. 